\title{
A UNIVERSIDADE E SUA FUNÇÃ̃O SOCIAL: OS AVANÇOS DA EaD E SUAS CONTRIBUIÇÕES NOS PROCESSOS DE ENSINO E APRENDIZAGEM
}

Andréia Morés ${ }^{1}$

\begin{abstract}
Resumo
A presente investigação está vinculada aos estudos realizados na tese de doutorado, na qual se investigaram os Cursos de Pedagogia EaD da UCS e UFRGS, tendo-se o objetivo de compreender a função social da universidade frente aos avanços da $\mathrm{EaD}$ e suas contribuições nos processos de ensino e aprendizagem. O método adotado para a investigação foi o Estudo de Caso, referendado por Yin (2005). A coleta de dados para a constituição de cada caso abarcou a análise de documentos institucionais e entrevistas semiestruturadas. O lastro teórico que embasou a pesquisa foram os estudos apresentados por Belloni (2003), Chauí (2001), Santos (2004, 2005), Leite (2005), entre outros. Portanto, os resultados alcançados potencializaram a função social da universidade, e os avanços da EaD proporcionaram a expansão, a democratização do acesso e o desenvolvimento de práticas com aproximações inovadoras nos processos de ensino e aprendizagem na universidade.
\end{abstract}

Palavras-chave: Universidade; Instituição Social; Pedagogia Universitária; Educação a Distância

\section{CAMINHOS INTRODUTÓRIOS}

\footnotetext{
${ }^{1}$ Doutora em Educação pela Universidade Federal do Rio Grande do Sul - UFRGS. Professora do Centro de Ciências Humanas e da Educação, da Universidade de Caxias do Sul - UCS. Endereço: Rua Francisco Getúlio Vargas, 1130- Bloco E - CEP 95070-560 - Caxias do Sul - RS, Brasil. Endereço eletrônico: anmores18@hotmail.com
} 
MORÉS, A.

No presente estudo contempla-se a educação superior mediante os referendos de Chauí (2001), Harvey (1992), Panizzi (2002), Santos (2004, 2005), Leite (2005) e outros autores que apresentam, de forma crítica, o desenvolvimento desse processo. Objetiva-se, através dessas leituras, compreender a função social da universidade, articulada à visão democrática, emancipatória e inovadora e suas contribuições nos processos de ensino e aprendizagem.

A partir dessa visão adentra-se nos estudos da expansão da educação superior, com base em teorias e também na legislação que regulamenta a educação superior, contendo os avanços da educação a distância $(\mathrm{EaD})$ e suas contribuições para os processos de ensino e aprendizagem na universidade.

Para o desenvolvimento desta investigação utilizou-se a metodologia qualitativa, com ênfase no estudo de caso, embasada nos autores Bogdan e Biklen (1994) e Yin (2005). Escolheu-se para o desenvolvimento da investigação o método do estudo de caso, o qual possibilita a investigação do contexto na vida real em que ele acontece, permitindo, assim, que se investiguem os cursos de Pedagogia EaD na UCS e UFRGS.

\section{A FUNÇÃO SOCIAL DA UNIVERSIDADE}

A universidade é uma instituição social que tem a sociedade como seu princípio e sua referência normativa e valorativa, estando fortemente apoiada nos princípios sociais aos quais pertence. Assim, a universidade, além de refletir os conhecimentos e as relações sociais, também possibilita transformar as formas de ver, compreender e produzir para além do presente, com visões futuras, projetando novas ações.

A universidade, no dizer de Chauí (2001), entendida como organização social, é regida por ideias de gestão, planejamento, previsão, controle e êxito. Assim, não lhe compete mais discutir ou questionar sua própria existência, sua função, seu lugar no interior da luta de classes. Sua prática social é definida pela sua instrumentalidade, ou seja, a instituição percebe a divisão social, econômica e política da sociedade em que está inserida, e desse lugar repensa a si mesma, sua função social, com práticas fundadas no reconhecimento público de sua legitimidade e de suas atribuições.

O acesso ao conhecimento técnico e científico sempre teve importância na sociedade capitalista por oferecer diferencial competitivo. O próprio conhecimento torna-se um instrumento privilegiado para a tomada de decisões mais bem-sucedidas e lucrativas, principalmente quando a educação está contida na concepção de mercadoria-chave "a ser produzida e vendida a quem pagar mais" (HARVEY, 1992, p.63). 
A UNIVERSIDADE E SUA FUNÇÃO SOCIAL: OS AVANÇOS DA EaD E SUAS CONTRIBUIÇÕES NOS PROCESSOS DE ENSINO E APRENDIZAGEM

Chauí (2001) e Santos $(2004,2005)$ oferecem um referencial importante que ajuda a entender a multiplicidade de funções que a universidade foi assumindo ao longo do tempo. Segundo Santos $(2004,2005)$, para entender a universidade há que se tomar como ponto de partida a ideia de que ela se encontra diante de uma situação complexa, sendo duplamente desafiada pela sociedade e pelo Estado. Isto porque a universidade tem sido cada vez mais exigida frente às novas expectativas e solicitações de uma sociedade em transformação, em que as políticas de financiamento tornam-se cada vez mais restritivas por parte do Estado. Para enfrentar essa situação de dupla tensão, Santos (2004) diz que a universidade precisa repensar sua trajetória e assumir os desafios que lhe estão sendo impostos.

O caminho proposto por Santos se direciona a um projeto democratizante e emancipatório, voltado às exigências da contemporaneidade marcada, principalmente, pela exclusão social (SANTOS, 2004). As transformações recentes no sistema de Educação Superior e seu impacto nas universidades exigem reorientação e reorganização profundas para que a universidade possa responder de modo criativo e eficaz aos problemas com os quais se defronta.

Segundo Santos (2005), o relatório da Organização para Cooperação e Desenvolvimento Econômico (OCDE), de 1987, é um exemplo da tentativa de tornar a universidade uma instituição de caráter pragmático-político. A OCDE atribui à instituição dez funções:

Educação geral pós-secundária; investigação; fornecimento de mão-de-obra qualificada; educação e treinamento altamente especializados; fortalecimento da competitividade da economia; mecanismos de seleção para empregos de alto nível, através de titulação; mobilidade social para os filhos de operários; prestação de serviços à região e à comunidade local, paradigmas de aplicação de políticas nacionais (como a igualdade de oportunidades) e preparação para os papéis de liderança social (SANTOS, 2005, p. 189).

Outra investida a favor dessa perspectiva é a inclusão do Ensino Superior entre os serviços comerciais regulamentados pela Organização Mundial do Comércio (OMC). As políticas implementadas pela OMC favorecem a comercialização internacional dos serviços de educação, assemelhando-os a simples mercadorias (PANIZZI, 2002; SANTOS, 2004). Contudo, a universidade parece manter a mesma formulação de seus objetivos e funções, ou seja, o ensino das profissões, a investigação científica e a prestação de serviços.

É óbvio, portanto, que existem reformas da educação superior, porém, o verdadeiro impacto das mudanças e reformas universitárias acontece concretamente nas políticas para a educação, que também assumem a perspectiva pragmático-política. Nessa situação, o objetivo das reformas universitárias passa a ser mais o de "manter as contradições sob controle através 
MORÉS, A.

da gestão das tensões que elas provocam" (SANTOS, 2005). As reformas visam amenizar, dispersar ou gerenciar essas tensões ao deixarem de assumir os princípios básicos que garantem a construção de um projeto democratizante e emancipatório para a sociedade (SANTOS, 2004).

No século XXI, de acordo com Santos (2005), as reformas deverão partir da constatação da perda da hegemonia e se concentrarem na legitimidade, assumindo que a universidade só existe quando há formação profissional, pesquisa e extensão. Sem qualquer uma dessas funções há Ensino Superior, mas não há universidade. Portanto, a universidade implica produção do conhecimento das relações sociais e produtivas, e ao atuar sobre elas pode transformá-las e ser transformada, devolvendo um novo conhecimento à sociedade mediante pesquisa, ensino e extensão.

\begin{abstract}
Em defesa da educação como bem público, Panizzi (2002) retoma a natureza da universidade como a instituição do debate e da reflexão. Nesse sentido, a universidade precisa assumir que a discussão acadêmica, a pesquisa científica e o acesso ao conhecimento não conhecem fronteiras. Essa perspectiva coloca a universidade diante dos desafios contemporâneos do mundo globalizado. O que está posto para a sociedade, portanto, é o destino do conhecimento como patrimônio social, e da educação como bem público. Esses compromissos devem ser afirmados e reafirmados pela universidade junto à pertinência da educação na relação às demandas sociais. Conforme diz o autor, as universidades têm extraordinária importância para nossas sociedades como lugar da diversidade cultural e da pluralidade ideológica, do debate e do diálogo que constroem sujeitos e coletividades, da crítica comprometida com a ética, que busca ser verdadeira e justa (PANIZZI, 2002, p. 13).
\end{abstract}

Contudo, compreende-se que a universidade é, acima de tudo, uma instituição emancipatória, que se propõe a atender as demandas internas e externas da sociedade, sem se fechar em si mesma. Ao mesmo tempo, almeja e planeja objetivos que desafiem o seu presente e preparem o tempo futuro. No dizer de Leite (2005, p. 26),

[...] a universidade inovadora e antecipatória deveria resguardar o equilíbrio entre valores éticos e culturais, preservar sua função de lúcida consciência crítica da sociedade de seu tempo justamente com a criação, preservação e difusão do conhecimento.

Dessa forma, compreende-se que a universidade inovadora deve contemplar novas articulações nas relações que estabelece entre a produção de conhecimentos e as relações humanas imbricadas nesse processo. Sob a ótica de Leite (2005, p. 27), "uma universidade será inovadora quando puder promover o necessário equilíbrio entre a busca de excelência, sem exclusão interna e externa e com compromisso de novas articulações sociais". Ainda conforme Leite (2005), o conceito de excelência está ligado ao conceito de qualidade institucional, e compreende que a excelência é "um superlativo da qualidade", e que, para 
A UNIVERSIDADE E SUA FUNÇÃO SOCIAL: OS AVANÇOS DA EaD E SUAS CONTRIBUIÇÕES NOS PROCESSOS DE ENSINO E APRENDIZAGEM

alcançar a excelência, a universidade não pode ser excludente em suas funções. Assim, complementa a autora, "a qualidade da universidade pode ser compreendida no seu marco institucional e na visão do aluno e da sociedade" (p. 27) quando ela é o que é e faz o que diz que faz.

Corrobora-se, portanto, o pensamento de Leite (2005, p.128) ao propor que a universidade brasileira trabalhe os princípios da democracia, não como categoria, mas "como uma prática educativa e pedagógica de construção de cidadania", contribuindo para a construção de uma nova cultura política que contemple o direito pedagógico da participação, do compromisso e da responsabilidade democrática.

\section{EXPANSÃO DA EDUCAÇÃO SUPERIOR: OS AVANÇOS DA EAD}

Ao ser promulgada a Constituição Federal de 1988 iniciou-se o debate sobre a nova Lei de Diretrizes e Bases da Educação Nacional (LDB), aprovada em 1996, sob o n. 9.394/96, prevendo variados graus de abrangência nos estabelecimentos de Ensino Superior público ou privado. A LDB promoveu relativa flexibilização da educação pós-secundária e superior, mas há uma discussão não esgotada sobre as possibilidades dadas pela autonomia universitária. Assim, instaurou-se a possibilidade de as universidades ampliarem as ofertas de cursos e vagas e propiciarem o avanço da $\mathrm{EaD}$ no Brasil.

A expansão da educação superior permitiu que a universidade estivesse mais próxima da sociedade a fim de melhor atender as suas necessidades. Dessa forma, nos últimos anos observou-se grande incentivo das políticas nacionais para a expansão da educação superior, através da criação de novas universidades, da abertura de novas vagas nas universidades já existentes, e a ampliação de novos campus e polos EaD.

Observou-se, também, que grande parte dos estudos existentes sobre o tema situam a EaD no debate contemporâneo, com realce para o potencial que essa modalidade pode oferecer à formação inicial e continuada, especialmente a de professores. Esses estudos também contribuíram para a superação do inevitável desafio de se repensar as práticas pedagógicas cristalizadas nas instituições educacionais frente ao acelerado avanço da ciência e das tecnologias da informação e comunicação que determinaram uma nova dinâmica social. Apontando para isso, há um imperativo de inovações educacionais que salientam a necessidade de novas estratégias didáticas na prática pedagógica em $\mathrm{EaD}$ aplicadas ao uso dos instrumentos interativos, mediando os interlocutores e aproximando os indivíduos que estão fisicamente distantes e envolvidos nesse processo de ensino e aprendizagem. 
MORÉS, A.

A fundação da Associação Brasileira de Educação a Distância (ABED), em 1995, que tem atuado em favor de uma mudança cultural em relação à EaD no Brasil, contribuiu para ampliar esse debate, a fim de eliminar os preconceitos ainda vigentes contra o ensino e a aprendizagem flexibilizados pela educação presencial possibilitada pelas TIC.

De acordo com a UNESCO (1998), a EaD constitui-se em fator inovador dos sistemas educativos por sua capacidade de criação, de flexibilidade, de uso intensivo das tecnologias, de estratégias de aprendizagem capazes de responder às novas solicitações e às urgentes demandas sociais, antes desconhecidas ou inexistentes. Assim,

[...] las enseñanzas abiertas y a distancia tienen un carácter innovador, por su método, por su flexibilidad para facilitar cualquier tipo de aprendizaje y responder a las demandas más variadas, por el uso intensivo de los medios de comunicación y las nuevas tecnologías de la información, por su economía y escala y porque exigen el compromiso personal con el auto aprendizaje, que es a la vez condición y objetivo de toda formación de calidad. Estas innovaciones puden ser, y de hecho están siendo, fermento renovador para la educación tradicional (UNESCO, 1998, p.16).

Segundo a UNESCO, a EaD busca atender a grandes contingentes de alunos de modo mais efetivo, tendo o cuidado com os riscos de reduzir a qualidade dos serviços decorrentes da ampliação do número de alunos atendidos. A EaD tornou-se, assim, um desafio aos sistemas educacionais no início do século XXI.

De acordo com a UNESCO (1998) e com a política de educação brasileira, é importante a oferta de oportunidades de educação permanente, que contemple a flexibilização curricular e a qualidade nos processos de ensino e aprendizagem. Segundo Formiga (2003),

\footnotetext{
nesse sentido, com a implementação de universidades corporativas, a expansão a educação profissional, a flexibilização das estruturas educacionais posteriores ao ensino médio, e, sobretudo, a introdução de novas tecnologias de comunicação e informação ao processo de ensino e aprendizagem - onde se inclui a Educação a Distância - são instrumentos que não podem ser esquecidos e devem ser amplamente utilizados no Brasil com o objetivo de contribuir para a superação dos impasses históricos do sistema educacional brasileiro, especialmente a Educação Superior (p.425).
}

Nessa direção, observa-se um cenário de intensas modificações, em que o conhecimento é produzido, sistematizado e reelaborado em escala de alta velocidade, pois, "a nova dinâmica de educação pode ser assumida em uma premissa: educação em todo lugar, a todo o tempo e sob demanda ou adaptada às necessidades do indivíduo ou de grupos específicos" (FORMIGA, 2003, p. 421). 
A UNIVERSIDADE E SUA FUNÇÃO SOCIAL: OS AVANÇOS DA EaD E SUAS CONTRIBUIÇÕES NOS PROCESSOS DE ENSINO E APRENDIZAGEM

A EaD está se tornando cada vez mais um elemento regular dos sistemas educativos, necessário não apenas para atender a demandas, mas assumindo funções de crescente importância. Na legislação educacional brasileira, segundo o texto do Decreto-Lei n. 2.494, de 10/02/1998, a seguinte definição de EaD caracteriza essa forma de ensino:

Art. $1^{\circ}$. Educação a distância é uma forma de ensino que possibilita a autoaprendizagem, com a mediação de recursos didáticos sistematicamente organizados, apresentados em diferentes suportes de informação, utilizados isoladamente ou combinados, e veiculados pelos diversos meios de comunicação.

Nessa definição há uma abordagem ampla sobre a $\mathrm{EaD}$, fazendo menção aos princípios da autoaprendizagem, aos modos de veiculação, abordando os diversos meios de comunicação e o uso sistemático e organizado de diferentes recursos didáticos e tecnológicos. Confirma, assim, a concepção atual de EaD defendida pelo Ministério da Educação²

A Educação a Distância é a modalidade educacional na qual a mediação didáticopedagógica nos processos de ensino e aprendizagem ocorre com a utilização de meios e tecnologias de informação e comunicação, com estudantes e professores desenvolvendo atividades educativas em lugares ou tempos diversos (MEC, 2010).

A $\mathrm{EaD}$, no Brasil, portanto, não é um método de ensino, mas uma modalidade educacional que pode ser adaptada a diferentes métodos e abordagens pedagógicas, em que, permeada pelas tecnologias, é compreendida como um sistema aberto de interconexões permanentes com outras práticas.

Refletindo-se sobre esse contexto da $\mathrm{EaD}$, percebe-se que a universidade, na condição de instituição de Educação Superior, passa a assumir um novo papel, devendo catalisar redes de conhecimento e pesquisa, sistematizando e disseminando entre todos os segmentos da sociedade os benefícios do desenvolvimento científico e tecnológico, em busca de proposições que atendam as necessidades dos novos tempos e dos novos cenários. Essa nova proposta de conhecer o processo de ensinar e aprender a distância visa ao questionamento da $\mathrm{EaD}$ sobre a forma prepotente ou única de educação do futuro. Tentar viabilizá-la garante projetos acadêmicos que possibilitem uma educação para todos, e as mudanças produzidas pelos avanços tecnológicos precisam ser consideradas conquista da humanidade, do mesmo modo que a tecnologia deve propiciar avanços no campo da educação superior para todos.

No entanto, considera-se esse fato um desafio para a universidade a fim de que ofereça novas formas de acesso ao conhecimento, favorecendo a compreensão de ideias, de um

\footnotetext{
2 http://portal.mec.gov.br/seed/index.php?option=com_content\&task=view\&id=248\&Itemid=426
} 
MORÉS, A.

pensamento crítico respaldado em um processo de ensino e aprendizagem social e democrático, mediante novas tecnologias.

\section{CAMINHOS INVESTIGATIVOS}

O embasamento metodológico desta investigação contempla a abordagem qualitativa, enfatizando-se o Estudo de Caso. Segundo Yin (2005),

[...] o estudo de caso é uma investigação empírica que investiga um fenômeno no seu ambiente natural, quando as fronteiras entre o fenômeno e o contexto não são bem definidas (...) em que múltiplas fontes de evidência são usadas (p. 13).

É a estratégia de investigação mais adequada quando queremos saber o 'como' e o 'porquê' de acontecimentos atuais (contemporary) sobre os quais o investigador tem pouco ou nenhum controle (p. 9).

Frente a essa compreensão, o método estudo de caso possibilita a investigação do contexto na vida real em que ele acontece, permitindo que se ilustrem certos tópicos, abarcando de modo descritivo e qualitativo o cotidiano; é o estudo da particularidade e da complexidade de um caso singular, levando a entender sua atividade dentro de importantes circunstâncias. Essa metodologia aborda "a observação detalhada de um contexto, ou indivíduo, de uma única fonte de documentos ou de um acontecimento específico" (BOGDAN e BIKLEN, 1994, p. 89).

Assim, aborda-se a presente investigação como um projeto de estudo de casos, envolvendo os cursos de graduação em Pedagogia, na modalidade EaD, da UCS e da UFRGS. Considerou-se pertinente investigar os dois casos pelo fato de o primeiro (a UCS) apresentar suas experiências enquanto universidade comunitária; e o segundo (a UFRGS) pelas experiências enquanto universidade pública federal, ambas com larga experiência na formação de professores, as quais passaram, na atual década, a investir na formação docente em EaD, em especial no Curso de Pedagogia, e, para ambas, esse é o primeiro curso de graduação na modalidade EaD.

A coleta de dados para a constituição de cada Caso abarcou a análise de documentos institucionais, em especial os Projetos Pedagógicos dos cursos, questionários e entrevistas semiestruturadas com alunos de ambos os cursos de Pedagogia EaD.

\section{- Contextualizando o Caso UCS}


A UNIVERSIDADE E SUA FUNÇÃO SOCIAL: OS AVANÇOS DA EaD E SUAS CONTRIBUIÇÕES NOS PROCESSOS DE ENSINO E APRENDIZAGEM

O Curso de Pedagogia EaD UCS iniciou em 2004, abarcando os municípios da região de abrangência da $\mathrm{UCS}^{3}$. Para a presente investigação contemplou-se o Projeto Pedagógico do curso de Pedagogia EaD implantado em 2007.

O sistema de orientação acadêmica do curso envolve a organização institucional de Professor Especialista, Orientador Acadêmico e Monitores, procedimentos educativos, pedagógicos, tecnológicos e administrativos que, no conjunto, objetivam o atendimento às necessidades de aprendizagem do aluno na forma de educação a distância (PROJETO PEDAGÓGICO, 2007).

O material didático é composto por cadernos didáticos, organizados por módulos, os quais apresentam: embasamento teórico e prático, atividades, pesquisas, tarefas dos alunos; hipermídia; audiovisuais; textos. O projeto pedagógico considera que o ambiente virtual de aprendizagem é um cenário que habita o ciberespaço, envolve diversas interfaces que favorecem a interação entre aprendizes, e deve incluir ferramentas para a atuação autônoma, oferecendo recursos de interação de uso individual e coletivo, favorecendo a aprendizagem.

O currículo está organizado em oito módulos, permeados por eixos temáticos, formando uma rede de conhecimentos, reflexões e práticas. Cada módulo reúne um conjunto de conhecimentos organizados independentemente das tradicionais disciplinas, estruturados a partir do entrelaçamento da teoria com a prática e apoiados na metodologia de resolução de problemas, e no final de cada semestre ocorre um Seminário Temático do Módulo.

A metodologia proposta no curso propicia o diálogo e o interesse, estimulando a autonomia de pensamento e a construção de aprendizagens significativas, buscando-se, assim, favorecer a metacognição, ${ }^{4}$ contemplando o desenvolvimento das capacidades de abstração e reflexão sobre a aprendizagem. Por sua vez, a avaliação é considerada um processo contínuo e complexo, e a avaliação da aprendizagem se realiza ao longo de cada etapa do curso, envolvendo as produções do aluno e o processo de desenvolvimento individual, explicitado em diferentes níveis de desempenho, conforme planejamento dos diferentes módulos.

\section{- Contextualizando o Caso UFRGS}

\footnotetext{
${ }^{3}$ Curso de Pedagogia teve oferta em 11 polos: Antônio Prado, Bento Gonçalves, Canela, Caxias do Sul, Guaporé, Montenegro, Nova Prata, São Marcos, São Sebastião do Caí, Terra de Areia e Vacaria.

4 "O desenvolvimento da metacognição pode ser entendido como a formação de uma competência transversal, no sentido de que atravessa todas as atividades de aprendizagem, em seus níveis crescentes de complexidade e abstração". (Projeto Pedagógico, 2007, p.43)
} 
MORÉS, A.

O curso de graduação em Pedagogia na modalidade EaD na UFRGS ${ }^{5}$ foi implantado em 2006. Para a presente investigação foram apropriados estudos vinculados ao Projeto Pedagógico do referido curso, primeira edição, 2006.

A estrutura curricular desse curso contempla um eixo articulador por semestre, coordenado por um professor, coordenador do eixo, o qual promove um planejamento em conjunto que visa, primordialmente, contemplar a necessária integração entre as Interdisciplinas e os enfoques temáticos. As Interdisciplinas estão sob a responsabilidade do professor articulador, dos professores colaboradores que acompanham a interdisciplina, dos bolsistas estagiários de pós-graduação e dos monitores de graduação.

Em relação ao uso do material pedagógico não se trata apenas de os professores trabalharem com a seleção de textos a serem lidos e comentados pelos alunos. Deve ser providenciada uma bibliografia de apoio para que os alunos-professores ampliem seu conhecimento sobre o tema em estudo. E o ambiente virtual deverá suportar as interações, apresentando as seguintes características: "permitir suporte a diversos tipos de atividades pedagógicas; desenvolvimento de atividades de solução de problemas; projetos individuais e conjuntos; oficinas tecnológicas; seminário temático e formação de grupos de estudou de trabalho, etc.” (PROJETO PEDAGÓGICO, 2006 p. 26).

O currículo está organizado em eixos temáticos. Os eixos são propostos por Interdisciplinas (grandes áreas que congregam conhecimentos específicos) e Seminário Integrador. Essa proposta curricular do curso se propõe a superar a dicotomia proporcionada pelos modelos convencionais de cursos à formação de professores, que tradicionalmente apenas teorizam sobre a prática, sem agregar-lhe inovações. Frente a essa superação, o currículo apresenta características interdisciplinares agregando e articulando conhecimentos específicos, teóricos e práticos em cada semestre.

A proposta metodológica prima pela metodologia interativa e problematizadora, e pelo uso intensivo da internet - ambiente virtual — para o desenvolvimento e acompanhamento das aprendizagens. Culmina, assim, com o processo de avaliação continuada, que consiste em dinamizar oportunidades de ação-reflexão sobre a prática docente e os conhecimentos adquiridos, mediante acompanhamento permanente de professores da Faced e dos designados pelas demais parcerias para sua efetivação conjunta.

\footnotetext{
${ }^{5}$ Esse curso atendeu aos professores que trabalham na rede municipal e estadual de ensino, em cinco polos: Alvorada, Gravataí, Sapiranga, São Leopoldo e Três Cachoeiras.
} 


\subsection{Análise dos casos sob o olhar dos alunos}

\section{PROCESSOS DE ENSINO E APRENDIZAGEM}

Nas narrativas dos alunos das instituições investigadas encontram-se diversas experiências vividas por esses acadêmicos durante sua formação.

É visível a importância da função social da universidade, na democratização do acesso e na expansão da $\mathrm{EaD}$, propiciando o ingresso e a realização de um curso superior com qualidade, indo ao encontro dos referenciais de Chauí (2001), Leite (2005) e Santos (2004 e 2005), em que destacam que a universidade precisa avançar em suas tradicionais concepções e práticas, atendendo as demandas da sociedade.

Assim, a modalidade EaD possibilita avançar para outros espaços e tempos para aprender, atendendo especialmente os profissionais que possuem longa jornada de trabalho e não dispõem de tempo para se deslocarem para cidades distantes, onde estão localizadas as universidades que, em sua grande maioria, ficam próximas de grandes centros.

O Curso EaD me auxilia bastante porque se eu tivesse que vir até a Universidade todo o dia, não sei se conseguiria, em virtude de todas as outras cargas, família em fim, na vida da gente às vezes vou estudar por umas $10 \mathrm{~h}$ da noite, porque é aquele horário que estou mais tranquila, que toda a gente já se acomodou, tudo o que agente tinha que fazer, aí senta e trabalha com tranquilidade. (Aluno - B/CX)

Considero os cursos EaD inovadores, pois possibilitam a formação e a qualificação, oportunizando a adequação de nossos horários às necessidades que temos. Ao mesmo tempo, são inovadores, pois utilizam para esta formação, recursos tecnológicos que são essenciais no mundo globalizado em que vivemos. (Aluno- $A / C X$ )

Percebe-se, nos fragmentos acima, que a EaD possibilitou a esses alunos participarem de um curso superior, necessário pela sua condição de professores, pois alguns deles possuem apenas o magistério. Para os demais alunos passou a ser uma nova profissão, sendo este um dos grandes objetivos da $\mathrm{EaD}$, tornando-se cada vez mais elemento regular dos sistemas de ensino, de forma a proporcionar uma educação de qualidade para todos, como se lê na seguinte afirmação:

Se não fosse o ensino a distância, pela qualidade e por ter um custo muito baixo, de não me obrigar frequentar uma sala de aula, de apresentar uma qualidade de material didático que eu 
MORÉS, A.

\section{considero excelente, eu não pensaria em fazer o curso. (Aluno} $C / C X)$

Nessa concepção, estão presentes três elementos que justificam a escolha pela EaD: a qualidade do curso, e, sendo um curso a distância, é necessário organizá-lo de tal forma para que não perca sua qualidade, mantendo o comprometimento institucional; o valor financeiro do curso, pois, para muitos, a escolha se baseou em um custo mais acessível, menor, cuja redução se justifica pelo fato de o curso não necessitar de ampla estrutura física; e, finalmente, por não ser necessária a frequência semanal do aluno em sala de aula, propiciando-lhe maior flexibilidade de horário/tempo e espaços.

Belloni (2003) corrobora essa visão e ressalta que a EaD apresenta transformações tanto nas finalidades sociais quanto nas estratégias e modalidades, notadamente com a introdução dos meios técnicos e com tendência à maior flexibilidade de acesso, currículos e metodologias:

A educação a distância surge, neste quadro de mudanças, como mais um modo regular de oferta de ensino, perdendo seu caráter supletivo, paliativo ou emergencial, e assumindo funções de crescente importância, principalmente no ensino póssecundário, seja na formação inicial (ensino superior regular), seja na formação continuada, cuja demanda tende a crescer de modo exponencial, em virtude da obsolescência acelerada da tecnologia e do conhecimento (BELLONI, 2003, p. 139).

Complementando seu pensamento, Belloni cita dois grandes desafios dos sistemas de educação superior para os quais a $\mathrm{EaD}$ pode contribuir significativamente mediante a “expansão significativa e diversificação da oferta de formação inicial (...); criação de novos modos de formação continuada (...)" (2003, p. 139). Isso tudo sem perder de vista as concepções humanistas de formação de um cidadão crítico e criativo, capaz de pensar e de inovar. Nesse bojo, tem-se as avançadas Tecnologias de Informação e de Comunicação (TIC) que proporcionam, progressivamente, maior flexibilidade e acessibilidade à educação, à cultura e ao desenvolvimento profissional da pessoa e contribuem para a criação dos sistemas educacionais do futuro.

Na concepção dos alunos, o curso de Pedagogia EaD apresenta elementos inovadores, destacando-se:

\footnotetext{
Sim, pois o uso da tecnologia está presente no nosso dia-a-dia cada vez mais $e$ as pessoas têm uma vida agitada, e um curso a distância proporciona uma 'auto-organização' do seu tempo. (Aluno $D / S M$ )
} 
A UNIVERSIDADE E SUA FUNÇÃO SOCIAL: OS AVANÇOS DA EaD E SUAS CONTRIBUIÇÕES NOS PROCESSOS DE ENSINO E APRENDIZAGEM

.... então foi bem inovador, nessa questão eu acho que a forma de ser colocado, também do guia pra gente estudar eu acho também que foi bem colocado ele é bem explicativo. (Aluno-B/CX)

Sim, este curso é inovador, como um curso a distância, e portanto, com características diferenciadas quanto à forma de ministrar o conhecimento, pode ser considerado muito inovador. (Aluna H/TC)

É Inovador, sim. Por não relevar atividades em cartilha e propiciar oportunidades de crescimento junto às novas tecnologias. (Aluno G/TC)

Nas falas acima transcritas há elementos que se referem às inovações na prática pedagógica desenvolvida no curso, a qual possibilitou um conhecimento mais amplo sobre elementos teóricos e práticos da pedagogia. Muitas interações estiveram presentes nas relações entre alunos, e entre alunos e professores, através de diversos meios: no presencial, em encontros coletivos; a distância, ampliadas por via escrita, por telefone/fax e por internet.

Percebe-se, também, na concepção dos alunos, que o presente curso apresenta elementos inovadores, buscando superar a lógica de atividades em cartilha, pré-elaboradas, diversificando os recursos e acesso às informações e aos conhecimentos, e contribuindo para a qualificação das práticas docentes, a fim de possibilitar autonomia aos processos de aprendizagem:

Propiciar uma autonomia para os alunos, de maneira que estes possam construir seus próprios conhecimentos.

Justamente refletir individualmente, em nossos lares, sobre os textos e materiais disponibilizados aos alunos. (Aluno G/TC)

Sair da postura de espectador e passar a intervir no próprio processo de aprendizagem.... o estudante constrói seu caminho e seu conhecimento, por ele mesmo, se tornando autodidata, ator $e$ autor de suas práticas e reflexões. (Aluno H/TC)

Fica explicito, na fala dos alunos, a importância da construção autônoma do conhecimento, havendo, assim, maior significado de apropriação desse conhecimento, em que o aluno avança do estágio de receptor de informações para o de ator desse processo.

Em relação ao processo de ensino e aprendizagem, Belloni (2003) discorre sobre a importância da aprendizagem autônoma cujo processo deve centrar-se no aprendente, mesmo 
MORÉS, A.

ao se considerar que a autoaprendizagem é tema relativamente novo no campo da $\mathrm{EaD}$. E, diz o autor,

um processo de ensino e aprendizagem centrado no estudante será então fundamental como princípio orientador de ações de EaD. Isto significa não apenas conhecer o melhor possível suas características socioculturais, seus conhecimentos e experiências, e suas demandas e expectativas, como integrá-las realmente na concepção de metodologia, estratégias e materiais de ensino, de modo a criar através deles as condições de autoaprendizagem (BELLONI, 2003, p. 31).

Portanto, a EaD deve proporcionar condições para a autoaprendizagem, ou seja, para uma aprendizagem autônoma, ativa e interativa, compreendendo esse processo não apenas como transmissão e aquisição de conhecimentos, mas como uma construção conjunta, em que alunos, tutores e professores se comprometam com a construção social do conhecimento, pois, de acordo com a visão defendida por Santos (2005) a função da universidade implica a produção de conhecimento das relações sociais e produtivas, e ao atuar sobre elas pode transformá-las e ser transformada, com o compromisso de devolver um novo conhecimento para a sociedade.

Assim, com esse compromisso surge a necessidade de buscar novos referenciais e práticas que atendam aos espaços e tempos diferentes, submetidos, também, a contextos diferentes, para além da sala de aula presencial, contemplando a $\mathrm{EaD}$.

Em alguns relatos, os alunos também afirmam que a metodologia de trabalho utilizada durante o curso tem "... características diferenciadas quanto à forma de ministrar o conhecimento, que pode ser considerado muito inovador" (Aluno H/TC). Assim, destacam o uso de metodologias diversificadas e apoiadas em elementos construtivos aos processos de aprendizagem, juntamente com os recursos tecnológicos educativos: "A utilização da tecnologia como metodologia de ensino também é uma inovação muito importante, pois nos abre caminhos à outras experiências e podemos levá-las para nossa prática docente" (Aluno I/TC).

Conforme diz Moran,

[...] ensinar e aprender com novas tecnologias é um desafio que até agora não foi enfrentado com profundidade. Temos feito adaptações do que já conhecíamos. O ensino presencial e o ensino a distância começam a ser fortemente modificados e todos nós - organizações, professores e alunos - somos desafiados a encontrar novos modelos em todas as situações. Ensinar e aprender hoje não se reduz a estar um tempo numa sala de aula. Implica modificar o que fazemos dentro desta sala de aula e, também, organizar ações de pesquisa e de comunicação que permitam a professores e alunos continuar aprendendo em ambientes virtuais, na TV ou acessando páginas na Internet, pesquisando textos, recebendo e enviando novas mensagens, entrando em salas de aula virtuais, divulgando seus trabalhos (2002, p. 2). 
A UNIVERSIDADE E SUA FUNÇÃO SOCIAL: OS AVANÇOS DA EaD E SUAS CONTRIBUIÇÕES NOS PROCESSOS DE ENSINO E APRENDIZAGEM

$\mathrm{O}$ ensino e a aprendizagem em $\mathrm{EaD}$ formam um processo complexo em uma sociedade em permanente mudança. Suas estratégias vêm sendo modificadas de modo a responder às novas demandas, notadamente com a introdução de meios técnicos e de flexibilidade maior quanto às condições de acesso a currículos, metodologias e materiais permeados pelas tecnologias.Assim, observa-se que a $\mathrm{EaD}$, ao longo de sua história, deu muita ênfase aos processos de ensino (estrutura organizacional, planejamento, produção de materiais) e pouco enfatizou os processos de aprendizagem (características e necessidades dos estudantes, modos e condições de estudos...), práticas estas que estavam mais relacionadas aos ensinantes do que aos aprendentes. $\mathrm{Na}$ atualidade, a $\mathrm{EaD}$, mediada pela tecnologia, apresenta características que propõem avanços aos processos de ensino e aprendizagem dessa modalidade.

Constata-se, também, nas falas dos alunos, uma relação didática e metodológica que primou por desenvolver o conhecimento de formas diferenciadas, gerando, conforme destaca o aluno D/SM, "uma nova maneira de aprender", imbricada em questionamentos, problematizações que indagam o aluno a pesquisar para aprender. $\mathrm{E}$ o aluno $\mathrm{C} / \mathrm{CX}$ assim se expressa:

Existiram momentos que a gente teve um pouco de dificuldades assim, porque surgem questões e o sistema nos obriga a pesquisar, mas por outro lado isso também, nos ajuda porque nos dá mais autonomia nessa busca de conhecimento.

Esse movimento metodológico de trabalho proporcionou desafios que, para alguns, soou acompanhado de dificuldades por não terem vivenciando antes esse processo, ou, muitas vezes, por ainda estarem voltados às tradicionais formas de ensino e aprendizagem. Esse trabalho, portanto, produz maior autonomia na instância do conhecer, sendo o aluno sujeito ativo do seu processo de aprender.

No entanto, destaca-se que a universidade, na condição de instituição social, deve propiciar mudanças significativas no modo de ver e pensar os processos de ensino e aprendizagem na educação superior, pois esta deixa de ser o ápice do percurso de aprendizado ao longo da vida para se tornar uma etapa desse processo e da educação permanente. A experiência educacional, certamente, deverá ser maior e mais profunda, valorizando um amplo espectro de situações de aprendizado, especialmente os papéis cujo reflexo seja valorizado pela sociedade.

\section{CAMINHOS CONCLUSIVOS}


MORÉS, A.

Ao se adentrar nos caminhos conclusivos deste artigo pode-se dizer que foi instigante a caminhada reflexiva e mobilizadora durante a construção deste texto, permitindo inserir no presente cenário a Universidade e sua função social, adentrando-se na conquista da expansão da Educação Superior e dos avanços da EaD e suas contribuições para os processos de ensino e aprendizagem, com base nos estudos de Chauí (2001), Leite (2005) e Santos (2004 e 2005).

De acordo com os dados construídos durante a investigação torna-se explicito que ambos os cursos potencializaram:

- democratização do acesso, aproximando a Universidade da Comunidade;

- inserção social, de modo a atender as demandas da sociedade, estando mais próximos da realidade dos estudantes;

- desenvolvimento de práticas com aproximações inovadoras que contribuem para os processos de ensino e aprendizagem na universidade;

- qualidade dos Cursos articulada aos pressupostos científicos, pedagógicos e tecnológicos;

Observa-se que os referidos cursos em EaD atenderam principalmente o público que reside em locais distantes das grandes cidades, onde se situam as universidades, e também os profissionais que desempenham longa jornada de trabalho, não podendo frequentar diariamente uma aula presencial, permitindo, assim, a expansão e a democratização do acesso à educação superior com qualidade.

Compreende-se, portanto, que o ensinar e o aprender ocorrem em vários contextos e instituições e ao longo de experiências vividas. E entende-se que a Universidade deve propiciar que os processos de ensino e aprendizagem na $\mathrm{EaD}$, mediados pelas novas tecnologias, sejam propulsores da dimensão humana, social e política, e que o processo pedagógico viabilize o diálogo com o conhecimento, visando à aprendizagem autônoma, ativa e interativa, referendada por Belloni (2003).

Finalmente, compreende-se que a universidade, na condição de instituição inovadora, assim defendida por Leite (2005), deve potencializar, em seus princípios institucionais, o zelo pela qualidade acadêmica entrelaçada às necessidades internas e externas, direcionando-a aos fins sociais e democráticos da educação, de modo a propiciar o acesso ao conhecimento e promover a inclusão social. Portanto, com base nos estudos de Santos (2004 e 2005), concluise que a universidade precisa ultrapassar os clássicos muros institucionais, os quais, por muito tempo, demarcaram seu território, sendo considerados único espaço de construção de conhecimento. 
A UNIVERSIDADE E SUA FUNÇÃO SOCIAL: OS AVANÇOS DA EaD E SUAS CONTRIBUIÇÕES NOS

PROCESSOS DE ENSINO E APRENDIZAGEM

THE UNIVERSITY AND ITS SOCIAL ROLE: THE EaD

ADVANCEMENTS AND THEIR CONTRIBUTIONS FOR THE

TEACHING AND LEARNING PROCESSES

\begin{abstract}
The present investigation is connected to studies carried out in the doctoral thesis that investigated the DE Pedagogy Courses at UCS and UFRGS universities with the objective of understanding the social role of the university in view of $\mathrm{EaD}$ advancements and their contributions for the teaching and learning processes. The adopted method for the investigation was the Study Case, as supported by Yin (2005). The data collection in order to build each case comprised analysis of institutional documents and semi-structured interviews. The theoretical background that provided the research base contemplated studies by Belloni (2003), Chauí (2001), Santos $(2004,2005)$ and Leite (2005), among others. Therefore, the achieved results empowered the social role of the university while $\mathrm{EaD}$ advancements fostered the expansion, the democratization of access and the development of practices with innovating approaches within the teaching and learning processes in the university.
\end{abstract}

Keywords: University; Social Institution; University Pedagogy; Distance Education

\title{
LA UNIVERSIDAD Y SU FUNCIÓN SOCIAL: LOS AVANCES DE LA EAD Y SUS CONTRIBUCIONES EN LOS PROCESOS DE ENSEÑANZA Y APRENDIZAJE
}

\section{Resumen}

La presente investigación está vinculada a los estudios realizados en teses de doctorado, donde se investigaron los Cursos de Pedagogía EaD (Educación a distancia) de la UCS y UFRGS con el_objetivo de comprender la función social de la universidad delante los avances de la $\mathrm{EaD}$ y sus contribuciones en los procesos de enseñanza y aprendizaje. El método adoptado para la investigación fue el Estudio de Caso, al que hace referencia Yin (2005). La recolección de datos para la constitución de cada caso incluyó el análisis de documentos institucionales y entrevistas semiestructuradas. La base teórica de la investigación fue 
MORÉS, A.

compuesta por los estudios presentados por Belloni (2003), Chauí (2001), Santos (2004, 2005), Leite (2005) y otros. Por lo tanto, los resultados que se han logrado potencializaron la función social de la universidad mientras los avances de la EaD proporcionaron la expansión, la democratización del acceso y la interacción en los procesos de enseñar y aprender en la universidad.

Palabras clave: Universidad; Institución Social; Pedagogía Universitaria; Educación a Distancia

\section{REFERÊNCIAS}

ABED. ASSOCIAÇÃO BRASILEIRA DE EDUCAÇÃO A DISTÂNCIA. Estatuto da Associação Brasileira de Educação a Distância - ABED Disponível em: $<$ http://www.abed.org.br/site/pt/institucional/docs_abed/estatuto/>. Acesso em: 30 de Out. 2010.

BELLONI, Maria Luiza. Educação a distância. 3. ed. Campinas: Autores Associados, 2003.

BOGDAN, R.; BIKLEN, S. Investigação qualitativa em educação: uma introdução à teoria $\mathrm{e}$ aos métodos. Portugal: Porto, 1994. Trad. da Editora Porto.

BRASIL. Lei $n^{o}$. 9.394, de 20/12/96. Estabelece as Diretrizes e Bases da Educação Nacional. Publicada no DOU de 20 dez. 1996.

. Decreto $n^{\circ} 2.494$, de 10/2/98. Regulamenta o art. 80 da Lei no .9 .394 , de 20/12/96, e dá outras providências. Publicada no DOU de 11/2/99.

. Ministério da Educação e Cultura. Disponível em: <http//www.mec.gov.br/>. Acesso em: 26 de jan. 2010.

CHAUÍ, Marilena. Escritos sobre universidade. São Paulo: Unesp, 2001.

FORMIGA, Marcos. Educação Superior e Educação a Distância. In: MORHY, Lauro (Org.). Universidade em questão. Brasília: Ed. da UnB, 2003.

HARVEY, David. Condição pós-moderna: uma pesquisa sobre as origens da mudança cultural. 5. ed. São Paulo: Loyola,1992.

LEITE, Denise (Org.). Reformas universitárias: avaliação institucional participativa. Petrópolis: Vozes, 2005.

MORAN, José Manuel. A Educação Superior a distância no Brasil. In: SOARES, Maria Susana Arrosa (Org.). Educação Superior no Brasil. Brasília: Coordenação de Aperfeiçoamento de Pessoal de Nível Superior, 2002. 
A UNIVERSIDADE E SUA FUNÇÃO SOCIAL: OS AVANÇOS DA EaD E SUAS CONTRIBUIÇÕES NOS PROCESSOS DE ENSINO E APRENDIZAGEM

PANIZZI, Wrana M. Universidade: um lugar fora do poder. Porto Alegre: Editora da UFRGS, 2002.

SANTOS, Boaventura de Souza. A Universidade no Século XXI: para uma reforma democrática e emancipatória da Universidade. São Paulo: Cortez, 2004.

Cortez, 2005.

. Pela mão de Alice: o social e o político na pós-modernidade. 7. ed. São Paulo:

UNESCO. Aprendizaje abierto y a distancia: perspectivas y consideraciones políticas.Universidad Nacional de Educación a Distancia, Instituto Universitario de Educación a Distancia, Cátedra Unesco de Educación a Distancia, Madrid, fev.1998.

UNIVERSIDADE DE CAXIAS DO SUL. Projeto Pedagógico - Curso de Licenciatura em Pedagogia: Docência para a Educação Básica séries inicias do ensino fundamental Educação a Distância. Caxias dos Sul: EDUCS, 2007.

UNIVERSIDADE FEDERAL DO RIO GRANDE DO SUL. Projeto Pedagógico do Curso de Graduação em Pedagogia - Licenciatura da UFRGS. Disponível em:

<http://paginas.ufrgs.br/sead/cursos/graduacao/>. Acesso em: 07 de set. 2010.

YIN, R. K. Estudo de caso: planejamento e método. 3. ed. Porto Alegre: Bookma, 2005.

Data de recebimento: $21 / 08 / 2016$

Data de aceite: $11 / 11 / 2016$ 